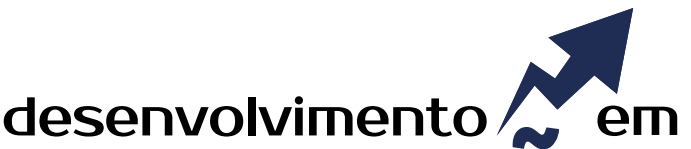 QUESTÃO
}

\section{O Impacto do Resultado do Banco Central do Brasil para o Cumprimento da Regra de Ouro}

\author{
http://dx.doi.org/10.21527/2237-6453.2020.53.120-137
}

Recebido em: 28/7/2019

Aceito em: 18/8/2020

\author{
Andre Nunes, ${ }^{1}$ Patricia Garrone Figueira Falcão, ${ }^{2}$ Noemia Monteiro, ${ }^{3}$ \\ Alexandre Nascimento de Almeida, ${ }^{4}$ Celso Vila Nova de Souza Junior ${ }^{5}$
}

\begin{abstract}
RESUMO
A Regra de Ouro, estabelecida no Brasil pelo artigo 167 da Constituição Federal de 1988, teve como objetivo melhorar a qualidade do gasto público, evitando que haja aumento de despesas correntes financiadas com a assunção de operações de crédito. Até o ano de 2000 observa-se no país constante desequilíbrio fiscal, ou seja, os gastos permaneceram superiores às receitas, impactando diretamente no crescimento econômico. Nesse contexto, foi editada a Lei Complementar 101/2000, conhecida como Lei de Responsabilidade Fiscal (LRF), definindo critérios, condições e limites à gestão orçamentária, financeira e patrimonial e criando novos mecanismos de controle dos gastos públicos. A forma como a Regra de Ouro foi instituída no Brasil, no entanto, permite seu cumprimento mesmo com o endividamento crescendo acima dos investimentos públicos. Isso ocorre porque o volume elevado de receitas financeiras de que dispõe o governo federal brasileiro, dentre elas o resultado positivo do Banco Central transferido ao Tesouro Nacional, contribuem para o seu cumprimento. $O$ objetivo deste artigo é analisar os impactos da transferência dos resultados do Banco Central, no período de 2008 a 2019, no cumprimento da Regra de Ouro no Brasil. As análises sugerem que, em especial a partir de 2010, o repasse do lucro operacional e o repasse decorrente das operações cambiais do Banco Central contribuíram para que o Tesouro Nacional cumprisse o mandamento Constitucional. Como consequência, todavia, o controle do endividamento público e do equilíbrio fiscal restou prejudicado.

Palavras-chave: Finanças públicas. Regra de ouro. Resultado do Banco Central.
\end{abstract}

\section{THE IMPACT OF CENTRAL BANK OF BRAZIL RESULTS ON FULFILLMENT WITH THE GOLDEN RULE}

\begin{abstract}
The Golden Rule, established in Brazil by article 167 of the Federal Constitution of 1988, aimed to improve the quality of public spending, avoiding an increase in current expenses financed by the assumption of credit operations. However, up to the year 2000, there is a constant fiscal imbalance in the country, that is, spending remained higher than revenues, directly impacting economic growth. In this context, Complementary Law 101/2000, known as the Fiscal Responsibility Law (LRF), defining criteria, conditions and limits for budgetary, financial and asset management and implementing new mechanisms for controlling public expenditures. However, how the Golden Rule was implemented in Brazil allows it to be fulfilled even with the indebtedness growing well above public investments. This is because the high volume of financial revenues available to the Brazilian federal government, among them, the positive result of the Central Bank transferred to the National Treasury, contributes to its fulfillment. In this sense, the objective of this article is to analyze the impacts of the transfer of the results of the Central Bank, in the period from 2008 to 2019, in compliance with the Golden Rule in Brazil. The analysis shows that, especially from 2010 onwards, the transfer of operating income and the foreign exchange operations of the Central Bank to the National Treasury contributed to the National Treasury demonstrating compliance with the Constitutional mandate. However, as a consequence, the control of public indebtedness and fiscal balance was impaired.
\end{abstract}

Keywords: Public finance. Golden rule. Central Bank Results.

\footnotetext{
${ }^{1}$ Doutor em Economia pela Universidade de Brasília (UnB). Professor da Universidade de Brasília (UnB). http://lattes.cnpq.br/ 8684723387252795. https://orcid.org/0000-0001-9928-6245. andrenunes@unb.br

2 Mestranda em Contabilidade pela Universidade de Brasília (UnB). Auditora do Tribunal de Contas da União (TCU). http://lattes.cnpq. br/9167424775127927.https://orcid.org/0000-0003-4640-9939. falcaopg@tcu.gov.br

${ }^{3}$ Mestranda em Contabilidade pela Universidade de Brasília (UnB). Contadora da Controladoria Geral da União (CGU). http://lattes.cnpq. br/6424752259272117. https://orcid.org/0000-0002-1823-6199. noemia104a@gmail.com

${ }^{4}$ Doutor em Engenharia Florestal pela Universidade Federal do Paraná (UFPR). Professor da Universidade de Brasília (UnB). http://lattes.cnpq. br/9028104786496275. http://orcid.org/0000-0002-9113-0729. alexalmeida@unb.br

${ }^{5}$ Doutor em Economia pela Universidade de Brasília (UnB). Professor da Universidade de Brasília (UnB). http://lattes.cnpq. br/9496068959100116. https://orcid.org/0000-0003-3623-9251. celso.vilanova@gmail.com
} 
A Regra de Ouro é um dispositivo inscrito na Constituição Federal de 1988 que proíbe que os governos dos três níveis da federação realizem operações de crédito que excedam o montante das suas despesas de capital. O dispositivo, inspirado em práticas internacionais e consagrado na literatura tradicional de finanças públicas, estabelece um orçamento dual, separando gastos de capital e gastos correntes, permitindo apenas aos primeiros o financiamento por meio de operações de crédito. A separação dos orçamentos tem como objetivo estabelecer um controle rígido para o orçamento corrente a fim de forçar seu equilíbrio, ao mesmo tempo em que flexibiliza a execução de investimentos que fortalecem o patrimônio público e geram benefícios para as gerações futuras.

Segundo Couri et al. (2018), a lógica da Regra de Ouro é simples e fácil de entender: se o total das receitas públicas não for suficiente para cobrir o montante das despesas públicas, sejam essas primárias ou financeiras, isso configura um déficit que terá de ser coberto por novas operações de crédito. Caso ocorra o contrário, ou seja, o total das receitas públicas é maior que o montante das despesas públicas, ocorre, então, um superávit, o qual permitirá ao ente público quitar débitos antigos, reduzindo seu financiamento.

Confirmando a relevância para manter as finanças públicas em equilíbrio, o descumprimento da Regra de Ouro e de outros preceitos da LRF constituem crime de responsabilidade, punível com o impedimento do gestor público, mais conhecido pelo seu nome em inglês: o impeachment. Apesar disso, no ano em que a LRF comemora 20 anos o quadro financeiro dos Estados permanece tão crítico quanto o era quando da sua criação, justamente com o objetivo de ajudar os entes federativos a reequilibrar as contas (KAFRUNI, 2020).

Especialistas da área de finanças responsabilizam a contabilidade criativa e as diferentes interpretações dos Tribunais de Contas dos Estados (TCEs), que aceitam a maquiagem fiscal apresentada pelos governos, pelo descumprimento da LRF ao longo dessas duas décadas. Nunes (apud KAFRUNI, 2020) ressalta que se a LRF tivesse sido respeitada muitos Estados não estariam na situação fiscal em que se encontram. Castello Branco (apud KAFRUNI, 2020) destaca que para a LRF ser mais efetiva é preciso uniformizar as metodologias de cálculo e mudar a forma de indicação dos ministros dos Tribunais de Contas. Salto (apud KAFRUNI, 2020) também destaca a LRF como um marco importante para as finanças públicas, pois estabeleceu um limite de gastos. $O$ autor afirma que, no entanto, a LRF tem sido burlada pela interpretação dada pelos TCEs.

No caso da União, especialistas em finanças públicas ressaltam que a Regra de Ouro vem sendo cumprida com a ajuda de receitas extraordinárias que entram no caixa do Tesouro Nacional. É o caso, por exemplo, das amortizações e juros que o Tesouro Nacional recebe de seus devedores (em especial os governos estaduais e municipais) e de instituições financeiras do governo, como o BNDES, dos resultados positivos do Banco Central que são transferidos ao Tesouro Nacional e da remuneração de serviços do Tesouro Nacional (COURI et al., 2018). 
A Lei 11.803/2008 modificou a forma de apuração do resultado do Banco Central do Brasil (Bacen). A partir da edição da Lei, o resultado do Banco Central passou a ser apurado separadamente: por um lado, apura-se o resultado relativo às operações com reservas cambiais depositadas no Bacen e, por outro, o resultado com as demais operações, dando tratamento diferenciado para cada um deles.

Desde as alterações instituídas pela edição da Lei 11.803/2008, e, ainda, considerando o grande volume das reservas internacionais entre os ativos do Banco Central, especialistas da área financeira e fiscal vêm apontando os riscos decorrentes para o equilíbrio fiscal das contas no Brasil.

Couri et al. (2018) salientam que, em decorrência do volume elevado de algumas receitas financeiras, o Brasil vem cumprindo a Regra de Ouro, apesar de o volume de operações de crédito crescer muito acima do montante dos investimentos.

Rytenband (2016) destaca que as alterações postas pela Lei 11.803/2008 vão de encontro ao que recomendam as normas internacionais de contabilidade em relação ao tratamento a ser dado aos resultados de um Banco Central.

Franco (2016), por sua vez, destaca que a Lei 11.803/2008 gera, onde originalmente não havia nenhuma transferência financeira, um fluxo monetário para a Conta Única, em contrapartida a um aumento do estoque de títulos na carteira do Banco Central, ou seja, do endividamento público.

O objetivo deste artigo é analisar os impactos da transferência dos resultados do Banco Central, no período de 2008 a 2019, no cumprimento da Regra de Ouro no Brasil. Para isso, este texto inicia-se com esta breve introdução. $O$ item a seguir apresenta a importância da instituição da Regra de Ouro para o equilíbrio das contas públicas no Brasil e em outros países. O item As alterações na apuração do resultado do Banco Central do Brasil aborda as alterações na apuração do resultado do Banco Central do Brasil, em razão da edição da Lei $11.803 / 2008$, bem como a relação entre o resultado do Banco Central e o cálculo da Regra de Ouro no Brasil. O item Impactos do resultado do Bacen no cumprimento da Regra de Ouro demonstra, com base em análises de Quadros e Gráficos com dados de 2008 a 2017, o impacto no cumprimento da Regra de Ouro em decorrência da edição da Lei 11.803/2008. Por fim, são apresentadas as considerações finais deste estudo e as referências bibliográficas empregadas na pesquisa.

\section{A BUSCA DO EQUILÍBRIO NAS CONTAS PÚBLICAS}

O Brasil vem buscando, desde a década de 90 do século 20, uma forma de adotar um conjunto de regras fiscais com o objetivo de evitar o aumento do déficit público. Por meio do aperfeiçoamento da gestão fiscal, vislumbra-se a redução do papel da política monetária e da taxa de juros no controle da inflação. Assim, a partir do final da década de 90 foi promovido um ajuste fiscal baseado em uma meta rígida de superávit primário (AFONSO, 2010).

A LRF teve origem na Assembleia Nacional Constituinte, na forma de um código de finanças públicas. Foi só em 1998, porém, que a emenda constitucional da reforma administrativa trouxe um comando para que o presidente da República enviasse ao Congresso Nacional o projeto de lei complementar de que trata o artigo 163 da Carta Magna. Surgiu, então, um amplo e ambicioso projeto, contendo princípios e regras de 
finanças públicas, o qual gerou polêmicas durante sua tramitação. O Congresso Nacional aprimorou, assim, a proposta do Poder Executivo Federal, mudando a estrutura e ampliando o alcance, aprovando o substitutivo com quórum de emenda constitucional. Alguns meses depois, o Supremo Tribunal Federal rejeitou a ação que alegava a inconstitucionalidade da lei como um todo e de dezenas de seus dispositivos, sacramentando sua incorporação ao arcabouço de normas nacionais (AFONSO, 2010).

A LRF trouxe a definição de critérios, condições e limites à gestão orçamentária, financeira e patrimonial, criando novos mecanismos de controle dos gastos públicos. Mendes (2015) avalia a questão cíclica dos gastos, ressaltando a característica do conjunto de regras fiscais que foram adotadas: quando a economia e a arrecadação estão crescendo, induzem o crescimento da despesa pública. Ou seja, em períodos de bom desempenho econômico, o crescimento do PIB e da receita estimula a expansão da despesa, fato que impede que se faça uma poupança como prevenção para os momentos em que o crescimento seja menor. Por outro lado, quando há uma diminuição de arrecadação, tem-se despesas altas e crescentes, esgotando, assim, o período de expansão. Neste momento, é necessário que se realize o ajuste fiscal.

O objetivo principal da LRF é garantir que os gestores públicos tenham compromisso com o bom uso dos recursos públicos por meio de ação planejada e transparente, visando o equilíbrio das contas públicas mediante o estabelecimento de limites (NASClMENTO; DEBUS, 2002).

No mesmo sentido, Nóbrega (2002) elenca os objetivos da LRF: i) instituir uma gestão fiscal responsável, com ênfase no controle do gasto e no endividamento; ii) prevenir desvios e estabelecer mecanismos de correção, por meio de punição aos administradores pelos desvios e modificar profundamente o regime fiscal brasileiro, com ênfase na transparência no setor público, com maior divulgação e entendimento das contas públicas.

A busca do equilíbrio nas contas públicas foi determinada pela Constituição Federal de 1988, ao vedar, em seu artigo 167, a realização de operações de crédito que excedam o montante das despesas de capital, salvo quando as operações de crédito sejam autorizadas pelo Poder Legislativo por maioria absoluta, por intermédio de créditos suplementares ou especiais, com finalidade precisa.

O artigo 167 da Constituição refere-se à chamada "Regra de Ouro", que tem como objetivo melhorar a qualidade do gasto público, evitando que haja aumento de despesas correntes financiadas com a assunção de operações de crédito. $O$ ideal é que haja aumento de despesas somente para cobrir investimentos e que o aumento das despesas correntes ocorra com parcimônia.

Segundo Pires (2019, p. 2),

O princípio econômico que justifica essa regra é que o investimento público, ao aumentar o estoque de capital público, beneficia várias gerações e não apenas a geração presente sobre a qual recai o ônus de financiar aquele investimento realizado na forma de impostos. Dessa forma, é desejável que os custos do financiamento desse tipo de despesa sejam absorvidos pelas várias gerações beneficiadas e não somente pela geração presente. 
Por sua vez, a LRF introduz no seu texto regras a respeito das operações de crédito, estabelecendo, em seu artigo $12, \S 2^{\circ}$, que "o montante previsto para as receitas de operações de crédito não poderá ser superior ao das despesas de capital constantes do projeto de lei orçamentária".

A LRF reforça a ideia de equilíbrio na proposta orçamentária, de forma que as operações de crédito previstas não ultrapassem o montante das despesas de capital. A Constituição Federal trata a matéria em termos de execução orçamentária, apenas com o acréscimo da exceção, que permite a utilização de créditos suplementares ou especiais. Quando da elaboração da proposta orçamentária, é vedada a previsão de operações de créditos superiores às despesas de capital, e durante a execução orçamentária o Poder Legislativo poderá, por maioria absoluta, aprovar créditos adicionais (suplementares ou especiais) que resultarão em extrapolação das operações de crédito em relação às despesas de capital (TAVARES et al., 1999).

A edição da Lei Complementar 101/2000 foi baseada em estudos e experiências de outros países, como Estados Unidos e Nova Zelândia, que adotaram normas visando a coibir o desvio e o desperdício de recursos públicos, tornando acessíveis à sociedade informações detalhadas sobre as finanças dos Estados e evidenciando a gestão de seus governantes (NASCIMENTO; DEBUS, 2002).

A Regra de Ouro foi instituída, com algumas variações, em diversos outros países, antes de ser incluída na CF brasileira de 1988. Na Alemanha, a Regra de Ouro foi introduzida na Constituição de 1969. Peculiaridades, no entanto, não impediram que o endividamento aumentasse de $17,5 \%$ do PIB quando foi efetivada, para $60 \%$ do PIB a partir de 2002. A crise financeira de 2008 tornou-se uma oportunidade para se criar outra regra de limite de endividamento (BAUMANN; DÖNNEBRINK; KASTROP, 2008).

No Reino Unido, a Regra de Ouro foi introduzida como uma forma de controle do endividamento público em 1997. No caso Britânico, era permitido aumentar o endividamento líquido, ou seja, abatendo-se a depreciação do estoque de capital. Ademais, o cumprimento da Regra de Ouro era verificado num período de ciclo econômico maior do que o exercício financeiro, o que conferia maior flexibilidade à regra (CHOTE; EMMERSON; TETLOW, 2009).

O Quadro 1 apresenta um resumo das ações realizadas em países que já buscavam o equilíbrio das contas públicas e realizaram estudos e aprovaram normativos para atingir tal fim.

As experiências de diversos países resumidas no Quadro 1 quanto ao estabelecimento de regras fiscais, contribuíram para que a reforma do Estado brasileiro incorporasse alguns princípios e normas fiscais parecidos ao instituído naqueles países. Como exemplo, a LRF tem traços da experiência da Nova Zelândia ao tratar da transparência; ou dos Estados Unidos, com a fixação de metas fiscais ou com a limitação de emissão de empenhos para garantir limites e metas orçamentárias (NASCIMENTO; DEBUS, 2002). 
Quadro 1 - Países que adotaram a Regra de Ouro

\begin{tabular}{|c|c|c|c|}
\hline PAÍs & DOCUMENTO & ANO & OBJETIVO \\
\hline \multirow[t]{2}{*}{ Alemanha } & $\begin{array}{c}\text { Constituição } \\
\text { Federal }\end{array}$ & 1969 & $\begin{array}{l}\text { O limite de cumprimento da regra de ouro era o exercício } \\
\text { financeiro, com possibilidades de "distúrbios no equilíbrio } \\
\text { macroeconômico". Este modelo dificultava o controle } \\
\text { da dívida pela regra de ouro em razão da: 1) dificuldade } \\
\text { para exercer o controle ex-post da regra, pois esta só } \\
\text { era observada quando da elaboração do orçamento; 2) } \\
\text { aplicação recorrente de excepcionalidades; 3) processo } \\
\text { de unificação da Alemanha ocidental e oriental; e 4) falta } \\
\text { de sanções ou de condições adicionais que assegurem a } \\
\text { sustentabilidade. }\end{array}$ \\
\hline & Aperfeiçoamento & 2011 & $\begin{array}{l}\text { Criada uma regra de limite de endividamento, onde o } \\
\text { déficit nominal estrutural (ajustado pelo ciclo econômico) } \\
\text { estaria limitado a } 0,5 \% \text { do PIB, sendo } 0,35 \% \text { para o governo } \\
\text { central e } 0,15 \% \text { para os governos regionais. Foi criada } \\
\text { uma conta corrente em que desvios da meta possam ser } \\
\text { compensados ao longo dos anos. Assim, um excedente } \\
\text { gerado em um determinado ano pode ser utilizado para } \\
\text { compensar uma frustração dessa meta em outro ano. }\end{array}$ \\
\hline $\begin{array}{l}\text { Estados } \\
\text { Unidos }\end{array}$ & $\begin{array}{l}\text { Budget } \\
\text { EnforcementAct (Lei } \\
\text { de Cumprimento do } \\
\text { Orçamento) }\end{array}$ & 1990 & $\begin{array}{l}\text { O Budget Enforcement Act (Lei de Cumprimento do } \\
\text { Orçamento) buscava conter rigidamente a despesa. O } \\
\text { reflexo deste documento na LRF pode ser visto no artigo } \\
\text { 9o, que limita a emissão de empenho (sequestration) - } \\
\text { proibição de empenharcomo propósito de garantir eficácia } \\
\text { dos limites e das metas orçamentárias estabelecidas para } \\
\text { as receitas e despesas. A compensação (pay as you go) } \\
\text { decorre do princípio de que aumentos de despesas devem } \\
\text { ser compensados com o aumento de receitas ou a redução } \\
\text { permanente de despesas. }\end{array}$ \\
\hline $\begin{array}{l}\text { Comunidade } \\
\text { Econômica } \\
\text { Europeia }\end{array}$ & $\begin{array}{l}\text { Comunidade } \\
\text { Econômica } \\
\text { Europeia (Tratado } \\
\text { de Maastricht) - } \\
\text { criação da União } \\
\text { Europeia } \\
\end{array}$ & 1992 & $\begin{array}{l}\text { Com o objetivo de estabelecer uma cooperação } \\
\text { econômica e política entre os países europeus por meio } \\
\text { do estabelecimento de metas de uma relação estável } \\
\text { entre dívida e produto interno bruto. }\end{array}$ \\
\hline \multirow[t]{2}{*}{ Reino Unido } & $\begin{array}{l}\text { Adota a regra de } \\
\text { ouro, em 1997, } \\
\text { assim que Gordon } \\
\text { Brown ascendeu } \\
\text { como Primeiro } \\
\text { Ministro }\end{array}$ & 1997 & $\begin{array}{l}\text { O endividamento somente era possível a partir de novos } \\
\text { investimentos, deduzido da depreciação do estoque de } \\
\text { capital e sem incorporação de despesas com amortização } \\
\text { da dívida. A regra considerava o ciclo econômico, ou seja, } \\
\text { era possível descumprir a regra ao longo do exercício } \\
\text { orçamentário, mas que ela deveria ser verificada nesse } \\
\text { período mais longo, o que cria mais flexibilidade para o } \\
\text { funcionamento da política fiscal. }\end{array}$ \\
\hline & $\begin{array}{l}\text { Office for Budget } \\
\text { Responsibility } \\
\text { (OBR); e Charter } \\
\text { for Budget } \\
\text { Responsability } \\
\text { (CBR) }\end{array}$ & 2008 & $\begin{array}{l}\text { Buscando regras fiscais mais flexíveis, foram criadas } \\
\text { o OBR - responsável pelas projeções fiscais de forma } \\
\text { independente - e o CBR, que é um contrato aprovado } \\
\text { pelo parlamento que traz um conjunto de regras fiscais } \\
\text { que define os objetivos para a política fiscal, inclusive para } \\
\text { a dívida pública. }\end{array}$ \\
\hline $\begin{array}{c}\text { Nova } \\
\text { Zelândia }\end{array}$ & $\begin{array}{l}\text { Nova Zelândia } \\
\quad \text { (Fiscal } \\
\text { Responsibility Act) }\end{array}$ & 1994 & $\begin{array}{l}\text { Trazer transparência aos relatórios de finanças públicas no } \\
\text { tocante às intenções do governo na área fiscal e encorajar } \\
\text { os governos a levar em conta as consequências de longo } \\
\text { prazo das decisões de política. }\end{array}$ \\
\hline
\end{tabular}

Fonte: LEITE, 2011. Elaboração própria. 
O Quadro 2 demonstra a avaliação do cumprimento da Regra de Ouro no período compreendido entre 2008 e 2019. Da análise do Quadro 2 depreende-se que a Regra de Ouro vem sendo respeitada pela União, pois o montante de operações de créditos contratadas se realiza em valores inferiores às despesas de capital de cada ano. Observa-se que o exercício de 2012 foi o ano que apresentou a melhor margem de suficiência, com resultado de $\mathrm{R} \$ 283,62$ bilhões, representando um excedente de despesas de capital em relação às despesas de operações de crédito realizadas no período. Em dezembro de 2017 o governo apresentou 28,8\% de margem de suficiência, ou seja, 96,80\% de despesas realizadas estão sendo cobertas com despesas com operações de crédito, 0 que acende o sinal vermelho para o cumprimento da regra de ouro para os próximos exercícios.

No exercício de 2019, no entanto, as operações de crédito superaram as despesas de capital, o que não acontecia desde a promulgação da Constituição Federal de 1988. Considerando-se o montante das operações de crédito de $\mathrm{R} \$ 1.057$ bilhão, e as despesas de capital executadas no montante de $\mathrm{R} \$ 872$ bilhões, houve um desequilíbrio de $\mathrm{R} \$$ 185 bilhões, o que configura descumprimento da Regra de Ouro. A CF permite que o CN autorize excepcionalmente essa situação por meio da aprovação de crédito suplementar, o que ocorreu com a aprovação da Lei 13.843/2019.

Quadro 2 - Avaliação do Cumprimento da Regra de Ouro Em R\$ bilhões

\begin{tabular}{|c|c|c|c|c|}
\hline ANO & $\begin{array}{c}\text { DESPESAS DE } \\
\text { CAPITAL } \\
\text { (a) }\end{array}$ & $\begin{array}{c}\text { RECEITAS DE } \\
\text { OPERAÇÕES DE } \\
\text { CRÉDITO } \\
\text { (b) }\end{array}$ & $\begin{array}{c}\text { MARGEM DE } \\
\text { SUFICIÊNCIA } \\
\text { (a - b) }\end{array}$ & $\begin{array}{c}\text { \% DESPESAS COBERTA } \\
\text { COM OPERAÇÕES DE } \\
\text { CRÉDITO } \\
\text { (b/a*100) }\end{array}$ \\
\hline 2008 & 526,35 & 429,24 & 97,11 & 81,55 \\
\hline 2009 & 597,91 & 405,42 & 192,49 & 67,81 \\
\hline 2010 & 603,65 & 512,61 & 91,04 & 84,92 \\
\hline 2011 & 667,15 & 567,36 & 99,79 & 85,04 \\
\hline 2012 & 743,97 & 460,35 & 283,62 & 61,88 \\
\hline 2013 & 712,49 & 552,31 & 160,18 & 77,52 \\
\hline 2014 & 940,64 & 844,42 & 96,22 & 89,77 \\
\hline 2015 & 863,63 & 801,48 & 62,15 & 92,80 \\
\hline 2016 & $1.039,93$ & 953,78 & 86,15 & 91,72 \\
\hline 2017 & 898,98 & 870,18 & 28,8 & 96,80 \\
2018 & 904,15 & 868,35 & 35,8 & 96,04 \\
2019 & 871,67 & $1.056,97$ & $-185,3$ & 121,26 \\
\hline
\end{tabular}

Fonte: www.tesourotransparente.gov.br.

Vale ressaltar que para o cálculo apresentado supra foi excluída do montante das despesas com operações de crédito a variação do "Colchão da Dívida", conforme prevê o artigo 6ㅇ, §4으 e §5으 da Resolução do Senado Federal 48, de 2007. Tal exclusão é necessária, uma vez que tais recursos, por se tratarem do saldo agregado das fontes orçamentárias e financeiras, o qual tem como destinação o pagamento da Dívida Pública Federal - DPF -, representa uma reserva financeira estratégica que o Tesouro Nacional possui. 
Seu objetivo é assegurar o pagamento dos vencimentos de um certo número de meses, colaborando, assim, para a redução da percepção do mercado quanto aos riscos da DPF. Ou seja, o cumprimento da Regra de Ouro não pode englobar tais recursos, uma vez que disso resultaria a falta de reservas para futuros resgates da dívida, o que poderia acarretar em novas emissões de títulos para recomposição da reserva (MENDES, 2016).

O Colchão de Liquidez é uma importante ferramenta para o gerenciamento da dívida pública. Ele é composto principalmente por recursos provenientes do refinanciamento da dívida de Estados e municípios, de receitas tributárias, da remuneração da Conta-Única e do resultado positivo do Banco Central. O Tesouro Nacional pode, também, recompor o Colchão por meio de emissões líquidas de títulos públicos (emissões superiores aos vencimentos).

\section{AS ALTERAÇÕES NA APURAÇÃO DO RESULTADO DO BANCO CENTRAL DO BRASIL}

A Lei 4.595 , de 31/12/1964, estabelecia no parágrafo único do artigo 8 que os resultados obtidos pelo Banco Central seriam incorporados ao seu patrimônio. Apenas em 1987, por força do Decreto-Lei 2.376, de 25/11/1987, que dispõe sobre a dívida mobiliária interna da União, houve a alteração do parágrafo único do artigo citado, estabelecendo:

Os resultados obtidos pelo Banco Central do Brasil, consideradas as receitas e despesas de todas as suas operações, serão, a partir de 10 de janeiro de 1988, apurados pelo regime de competência e transferidos para o Tesouro Nacional, após compensados eventuais prejuízos de exercícios anteriores (Dec. Lei 2.376/87).

Com a publicação da LRF o dispositivo contido no parágrafo único do artigo 8으 do Decreto-Lei 2.376 foi parcialmente alterado pelo caput e pelo parágrafo 10 do artigo 7응 da Lei de Responsabilidade Fiscal, que dispõe:

Art. 70 0 resultado do Banco Central do Brasil, apurado após a constituição ou reversão de reservas, constitui receita do Tesouro Nacional, e será transferido até o décimo dia útil subseqüente à aprovação dos balanços semestrais.

$\S 1$ ㅇ O resultado negativo constituirá obrigação do Tesouro para com o Banco Central do Brasil e será consignado em dotação específica no orçamento.

$\S 2$ ㅇ 0 impacto e o custo fiscal das operações realizadas pelo Banco Central do Brasil serão demonstrados trimestralmente, nos termos em que dispuser a lei de diretrizes orçamentárias da União.

$\S 3$ 3o Os balanços trimestrais do Banco Central do Brasil conterão notas explicativas sobre os custos da remuneração das disponibilidades do Tesouro Nacional e da manutenção das reservas cambiais e a rentabilidade de sua carteira de títulos, destacando os de emissão da União (BRASIL, 2000).

O resultado do Banco Central será analisado em dois momentos: antes e depois da edição da Lei $11.803 / 2008$, pois, desta forma, fica evidente o impacto dos mandamentos da Lei no cumprimento da Regra de Ouro.

O Banco Central detém, dentre outras competências, a de ser o único depositário das reservas oficiais de ouro e moeda estrangeira e de Direitos Especiais de Saque (MENDES, 2016). A partir de 2007 observa-se um aumento expressivo no saldo das re- 
servas internacionais em poder do Bacen, o que resultava em maior volatilidade do resultado do Banco em razão das oscilações na taxa de câmbio quando da apuração do estoque de reservas cambiais e derivativos. 0 Gráfico 1, a seguir, demonstra o montante desse aumento das reservas:

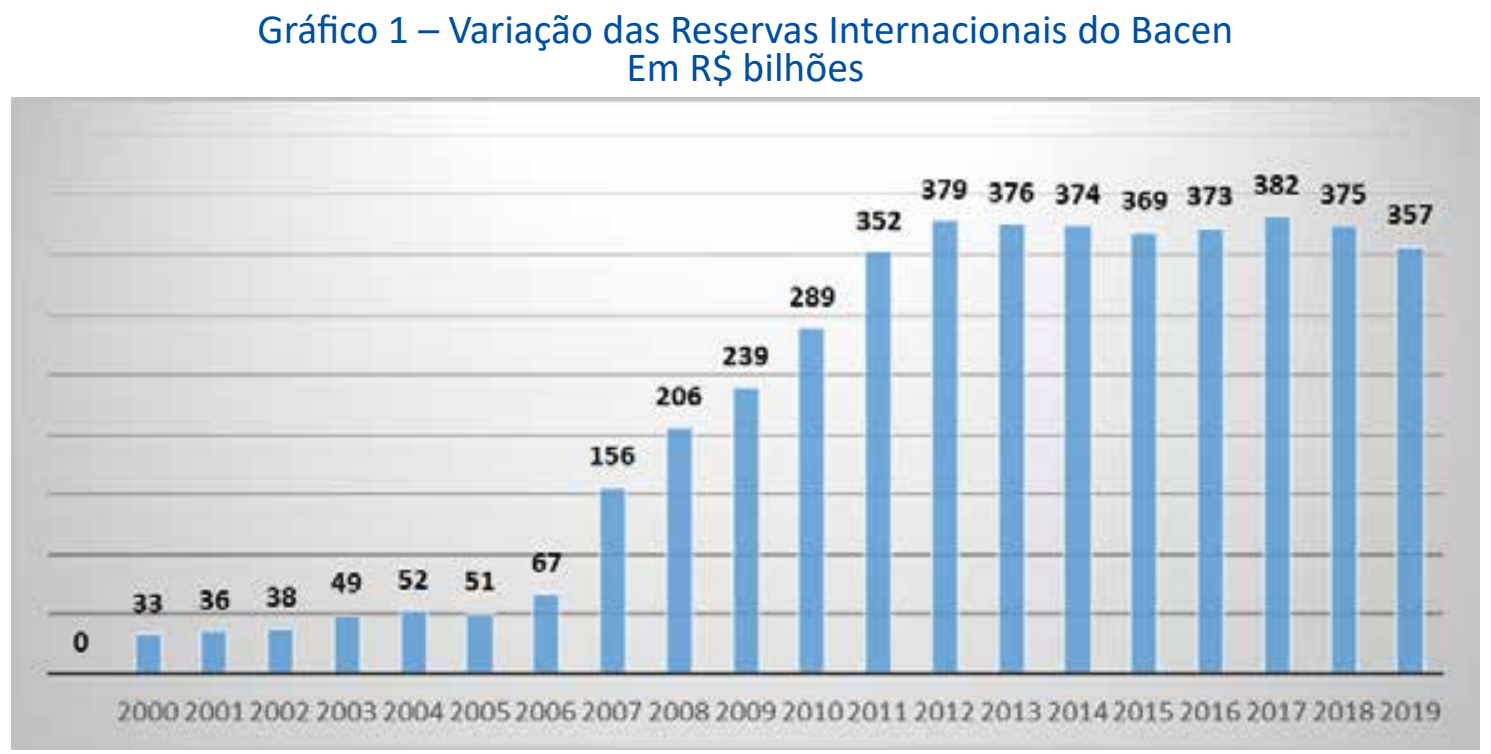

Fonte: Demonstrações Financeiras do Banco Central do Brasil, de 2000 a 2019. Elaboração própria.

Da análise do Gráfico 1 depreende-se que, de 2006 a 2012, o montante das reservas internacionais em poder do Bacen aumentou em $567 \%$. Essas reservas funcionam como uma espécie de seguro do país para lidar com momentos de alta ou queda expressiva do dólar, o que poderia prejudicar a economia brasileira (GOLLO, 2012).

Anteriormente a 2008, o resultado do Banco Central era calculado de forma unificada, e a constituição de reservas do Banco Central era regulada pelo artigo 2ㅇ e § 3ㅇda Medida Provisória 2.179-36/2001, que estabelecia o limite de 25\% para a constituição dessas reservas. Quando o resultado do Bacen fosse positivo, em obediência ao disposto no artigo 70 , efetuava-se a constituição de reservas de resultado no limite de $25 \%$ do resultado patrimonial. Assim, a reserva de resultado era apurada conforme a seguir:

\section{Reservas de Resultado $=$ Resultado do BACEN x 0,25}

A Lei 11.803/2008 trouxe inovações quanto à forma de apuração do resultado do Bacen, por meio da institucionalização da equalização cambial entre o Tesouro Nacional e o Banco Central, com o fim de se obter maior transparência dos resultados das operações bem como reduzir a volatilidade do resultado. $O$ artigo 60 da referida Lei estabelece:

Art. 60 O resultado financeiro das operações com reservas cambiais depositadas no Banco Central do Brasil e das operações com derivativos cambiais por ele realizadas no mercado interno, conforme apurado em seu balanço, será considerado: I - se positivo, obrigação do Banco Central do Brasil com a União, devendo ser objeto de pagamento até o décimo dia útil subseqüente ao da aprovação do balanço pelo Conselho Monetário Nacional; e

II - se negativo, obrigação da União com o Banco Central do Brasil, devendo ser objeto de pagamento até o décimo dia útil do exercício subseqüente ao da aprovação do balanço pelo Conselho Monetário Nacional (BRASIL, 2008). 
Dessa forma, diariamente passa a ser realizada a apuração do resultado financeiro com reservas cambiais e o resultado financeiro das operações com derivativos cambiais. Quando esse resultado for positivo, os valores serão destinados exclusivamente ao pagamento da Dívida Pública Mobiliária Federal (MENDES, 2016).

A metodologia de cálculo adotada após a edição da Lei 11.803/2008 separa as relações financeiras entre "Resultado de Demais Operações" e "Equalização Cambial", de forma que, havendo lucro em cada uma dessas rubricas, o Banco Central transfere o resultado positivo para o Tesouro Nacional em dinheiro; em caso de prejuízo, o Tesouro Nacional disponibiliza títulos na carteira do Banco Central para compensar as perdas com as demais operações, bem como o prejuízo com a equalização cambial (MENDES, 2016).

A Lei 11.803/2008 não alterou a forma de constituição de reservas, que continuou limitada a $25 \%$ da soma do resultado apurado no balanço do Banco Central, somente acrescentando a este percentual o resultado do cálculo das operações cambiais e das operações com derivativos (MENDES, 2016).

Assim, temos que o cálculo para a constituição de reservas passou a ser efetuado da seguinte forma:

Reservas de Resultado $=($ Resultado das Operações + Resultado da Equalização Cambial $) \times 0,25$

Ressalte-se que a Lei 11.803/2008, ao separar o resultado do Bacen em duas partes, criando regras específicas para cada uma delas, criou uma situação em que, ao invés de haver uma única transferência de valores, considerando a soma dos dois resultados (equalização cambial + outras contas), são feitas duas transferências distintas. Ou seja, se o resultado da equalização cambial for positivo em $R \$ 100$ bilhões, enquanto no mesmo período houver um resultado negativo no mesmo montante relativo às demais operações, em vez de se considerar que o resultado total for zero, e não se realizar nenhuma transferência de uma instituição para outra, a Lei 11.803/2008 estabelece que haverá um pagamento do Bacen ao Tesouro no valor de $\mathrm{R} \$ 100$ bilhões em dinheiro, e ainda uma transferência de títulos do Tesouro para o Bacen no mesmo valor. Tal situação acarreta um fluxo intenso de recursos entre as duas instituições, contrariando as boas práticas contábeis (MENDES, 2016).

Com a edição da Lei 11.803/2008, e a consequente separação do resultado das operações do Bacen do resultado da equalização cambial, verifica-se que os resultados do Banco Central, os quais desde 2000 constantemente apresentavam resultado negativo, passaram, a partir de 2008, a apresentar seguidos resultados positivos, com exceção dos anos de 2009 e 2016, conforme o Quadro 3 a seguir.

Quadro 3-Resultado do Bacen

Em R\$ milhões

\begin{tabular}{|c|c|c|}
\hline ANO & 10 SEMESTRE & 20 SEMESTRE \\
\hline 2008 & 3.172 .740 & 10.172 .653 \\
\hline 2009 & -941.601 & 6.550 .645 \\
\hline 2010 & 10.803 .195 & 4.926 .775 \\
\hline 2011 & 12.230 .706 & 11.240 .704 \\
\hline
\end{tabular}




\begin{tabular}{|c|c|c|}
\hline 2012 & 12.318 .246 & 12.296 .483 \\
\hline 2013 & 17.688 .071 & 14.267 .811 \\
\hline 2014 & 5.271 .503 & 25.655 .376 \\
\hline 2015 & 35.184 .659 & 41.521 .539 \\
\hline 2016 & -17.308 .089 & 7.780 .387 \\
\hline 2017 & 11.271 .662 & 14.709 .838 \\
\hline 2018 & 19.665 .292 & 25.554 .330 \\
\hline 2019 & 21.041 .908 & 64.534 .686 \\
\hline
\end{tabular}

Fonte: Demonstrações Financeiras do Banco Central do Brasil. Elaboração própria.

O Gráfico 2, na sequência, representa o resultado das operações do Banco Central em contrapartida ao resultado da equalização cambial, no período de 2008 a 2019.

Gráfico 2 - Comparação dos Resultados do Bacen Em R\$ bilhões

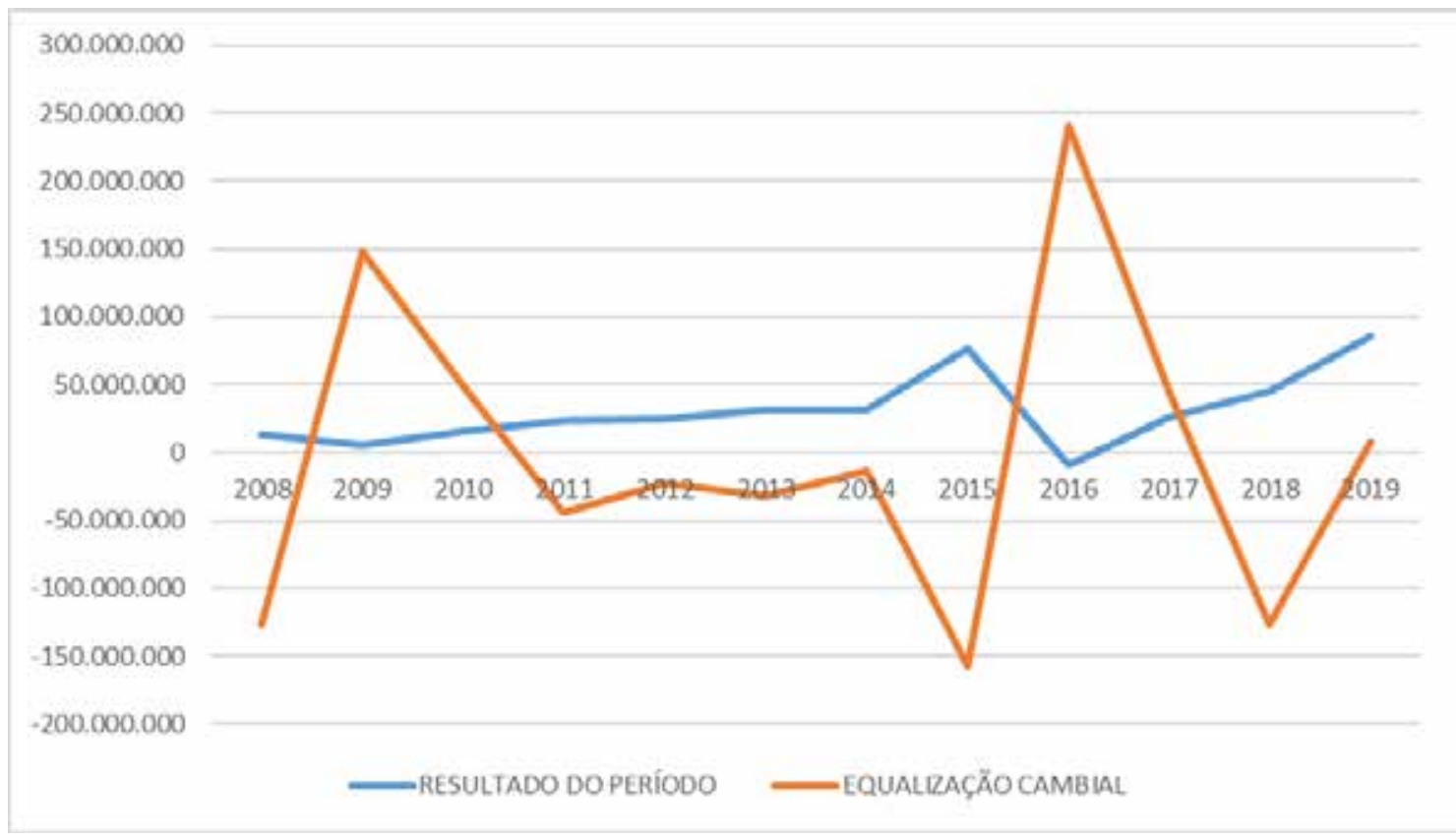

Fonte: Demonstrações Financeiras do Banco Central do Brasil. Elaboração própria.

Do Gráfico 2 depreende-se que no período de 2008 a 2019 o Banco Central apresentou resultado negativo das demais operações somente em 2016, enquanto o resultado da equalização cambial no período apresentou, em sua maioria, resultados negativos. Ou seja, no período analisado houve, após a constituição de reservas, o repasse semestral ao Tesouro Nacional, por meio de depósito na conta única, decorrente do lucro com as operações do Bacen. Ademais, em relação ao resultado da equalização cambial, houve transferência de títulos do Tesouro Nacional para cobrir os prejuízos do Bacen, exceto em 2009 e 2016, quando o Bacen novamente transfere recursos, em dinheiro, para o Tesouro Nacional (MENDES, 2016).

Destaque-se que o volume de reservas internacionais em poder do Bacen, constituído em títulos públicos e, principalmente, moeda estrangeira, notadamente o dólar, é utilizado pela autoridade monetária para regular a política cambial e monetária, assegurando a estabilidade e o poder de compra da moeda brasileira. Isto é, a fim de regular o 
regime de câmbio flutuante vigente no Brasil, o Bacen utiliza as reservas internacionais em seu poder em sentido contrário ao do mercado, vendendo dólar para evitar fortes valorizações do real (quer dizer, queda no valor do dólar), e comprando dólar em caso de forte desvalorização do real (isto é, aumento do valor do dólar).

Quando ocorre desvalorização do real em relação ao dólar, o valor das reservas internacionais, em reais, aumenta, gerando resultado cambial positivo para o Bacen. Quando ocorre o contrário, ou seja, quando o real se valoriza frente ao dólar, o Bacen registra resultado cambial negativo (ou prejuízo). A necessidade de o Bacen manter grande volume de reservas internacionais em seu patrimônio decorre dessa atuação da autoridade monetária (MENDES, 2016).

\section{IMPACTOS DO RESULTADO DO BACEN NO CUMPRIMENTO DA REGRA DE OURO}

Couri et al. (2018) apresentaram um estudo detalhado da Regra de Ouro no Brasil em comparação com outros países, explicando como é possível estabelecer uma regra de controle do endividamento por 30 anos, desde a Constituição de 1988, a qual foi formalmente cumprida sob condições de investimentos estáveis (ou decrescentes), elevados déficits correntes e endividamento crescente no âmbito do governo federal.

Os autores supracitados (2018) destacam que uma das explicações para que a Regra de Ouro no Brasil seja cumprida, mesmo com o endividamento crescendo muito acima dos investimentos públicos, é justamente o volume elevado de receitas financeiras de que dispõe o governo federal brasileiro, dentre elas o resultado positivo do Banco Central transferido ao Tesouro Nacional. Outras receitas financeiras citadas pelos autores como disponíveis em grande volume no caso brasileiro são: i) as provenientes de amortizações e juros que o Tesouro Nacional recebe de seus devedores (governos estaduais e municipais e instituições financeiras oficiais, como o BNDES); ii) a remuneração das disponibilidades financeiras do Tesouro Nacional depositadas na sua conta única no Banco Central (COURI et al., 2018).

Além de receitas financeiras em volume elevado, outra peculiaridade da Regra de Ouro no Brasil que contribui para seu cumprimento mesmo com o volume de operações de crédito crescendo muito acima dos investimentos públicos, é a abrangência maior da definição de despesas de capital. Assim, incluem-se entre as despesas de capital, além das aquisições de ativos fixos do governo federal, as transferências de capital que financiam os investimentos dos governos subnacionais e instituições privadas sem fins lucrativos (COURI et al., 2018).

Assim, a Regra de Ouro instituída no Brasil não exige equilíbrio do orçamento corrente, apenas fixa um teto para o déficit corrente em relação ao volume de receitas e despesas financeiras do governo federal. Considerando que ao longo dos anos, por motivos diversos, as receitas e despesas financeiras alcançaram volumes expressivos, isso elevou esse teto para o déficit corrente. Ou seja, a aplicação de uma Regra de Ouro conceitualmente mais ampla no Brasil permite seu cumprimento mesmo em períodos de elevado déficit corrente, desde que este déficit seja compensado por receitas ou despesas financeiras (COURI et al., 2018). 
Como agravante, Couri et al. (2018) indicam que parte considerável das fontes financeiras está relacionada a relações intra-setor público (como é o caso da relação Tesouro Nacional e Banco Central). Isso gera margem de manobra, flexibilizando o teto de déficit corrente. Lembrando que a configuração clássica da Regra de Ouro estabelece, simultaneamente, flexibilidade para a execução dos investimentos com controle rígido sobre o orçamento corrente.

A análise do Gráfico 3 demonstra o nível de influência da transferência do Resultado do Bacen no cumprimento da Regra de Ouro no Brasil. A linha azul representa a margem de cumprimento da Regra de Ouro de acordo com o cálculo oficial, ou seja, sintetiza em que medida as despesas de capital foram superiores ao fluxo de operações de crédito. A linha laranja representa a mesma margem sem incluir o resultado do Banco Central. Destaca-se, na análise do Gráfico 3, que haveria o descumprimento da Regra de Ouro desde 2015, caso não houvesse transferência de recursos relativa ao resultado do Bacen. As duas linhas encontram-se em 2019, uma vez que esse mecanismo foi alterado em decorrência da promulgação da Lei 13.820/2019, como será visto mais adiante.

\section{Gráfico 3 - Contribuição do Resultado do Bacen para o Cumprimento da Regra de Ouro} (Em R\$ bilhões a preços correntes)

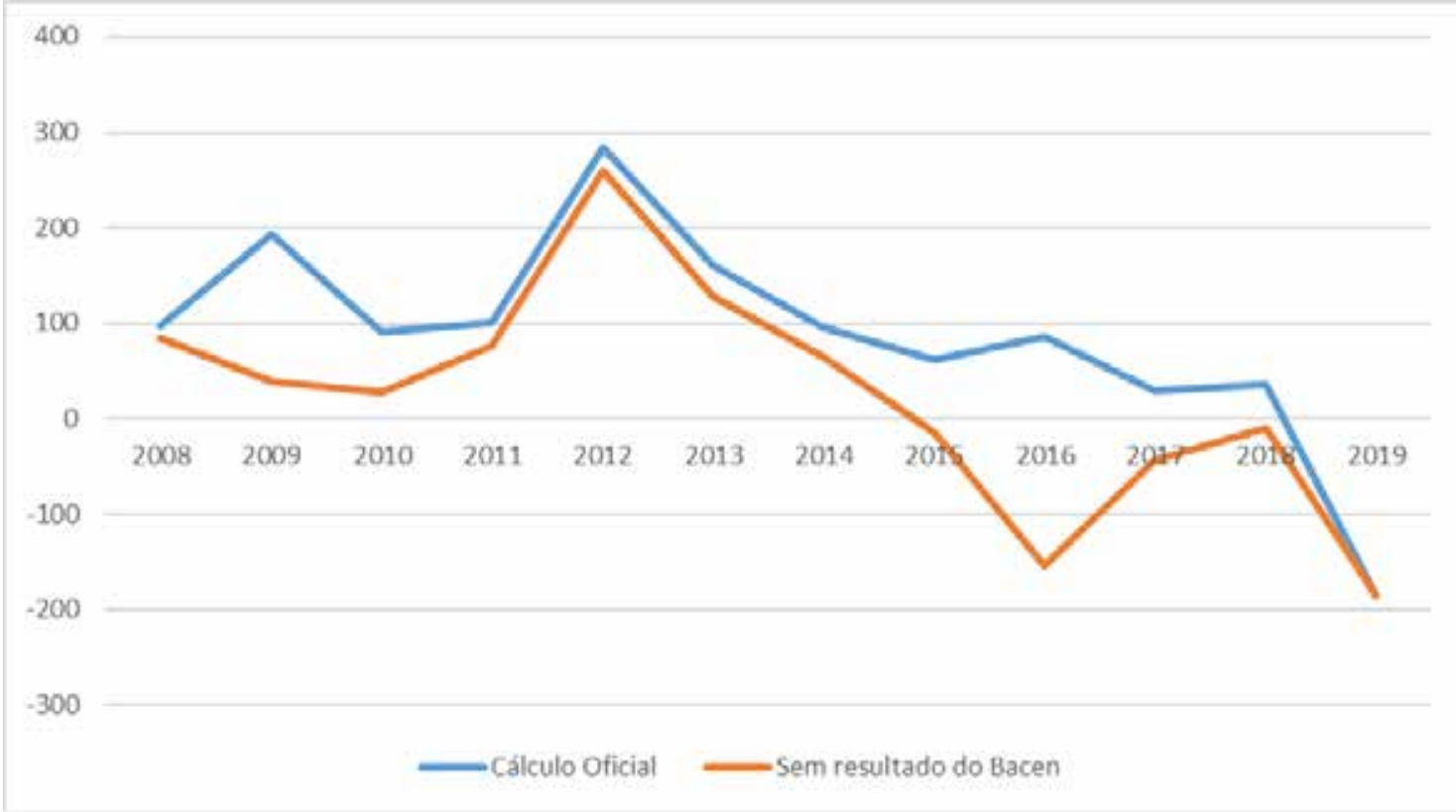

Fonte: Tesouro Transparente e Demonstrações Financeiras do Bacen. Elaboração própria.

Em outras palavras, da forma como foi introduzida a Regra de Ouro no Brasil, quanto maior o volume das receitas financeiras, menor a necessidade de realização de novas operações de crédito, contribuindo para o cumprimento da Regra de Ouro. Dentre as principais fontes que compõem a receita financeira, destacam-se: i) o resultado positivo do Banco Central; ii) o retorno de operações de refinanciamento, como as devoluções por parte do Banco Nacional de Desenvolvimento Social (BNDES); iii) o pagamento de juros e amortizações por parte de Estados e municípios; e iv) a remuneração da conta única (COURI et al., 2018).

O Gráfico 3 demonstra a influência das quatro receitas financeiras listadas anteriormente. Nota-se, a partir de 2008, ou seja, após a edição da Lei 11.803/2008, o impacto do resultado do Bacen no montante total das receitas financeiras da União, contri- 
buindo para o cumprimento da Regra de Ouro. A partir de 2009 é visível o crescimento do montante do repasse do lucro operacional e decorrente das operações cambiais do Bacen para o Tesouro, uma vez que tal período é marcado pela relevante desvalorização cambial, ao mesmo tempo em que o montante das reservas internacionais em poder do Bacen aumenta consideravelmente, conforme já visto antes (COURI et al., 2018).

Em 2017 ressalta-se o montante do retorno de dividendos de médio e longo prazos para a União. Destaque-se que tal receita financeira inclui a devolução de recursos do Banco Nacional do Desenvolvimento Econômico e Social (BNDES), que, em 2017, foi de $R \$ 100$ bilhões.

Em 2009 destaca-se o resultado do Bacen, em decorrência da forte desvalorização cambial resultante dos impactos da crise econômica de 2008, que se refletiu no Brasil em 2009.

Gráfico 4 - Evolução das Principais Receitas Financeiras da União Em R\$ bilhões

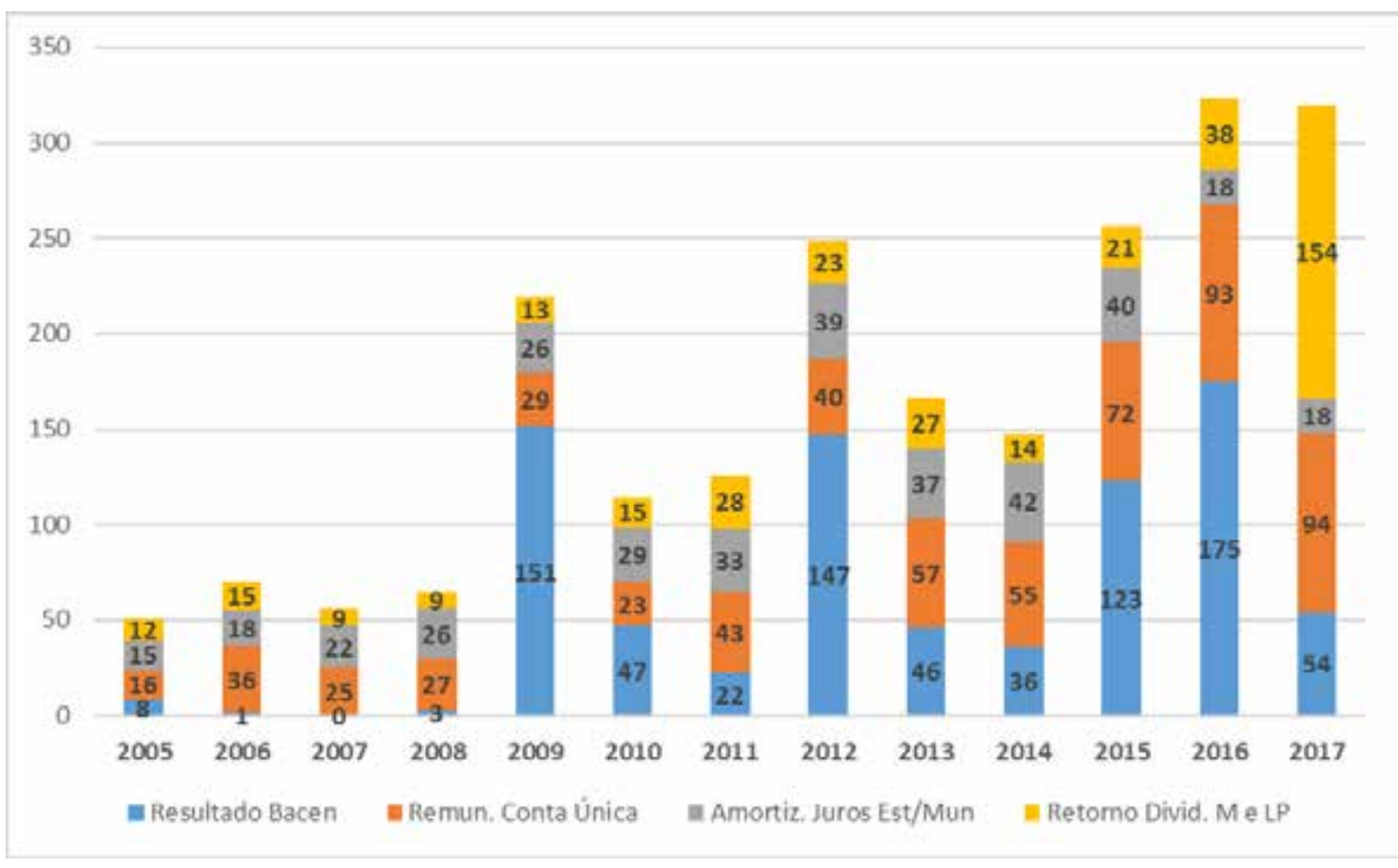

Fonte: COURI et al., 2018.

Vários autores apontam os impactos deletérios da Lei 11.803/2008 nas finanças públicas. Rytenband (2016) destaca que tais alterações ao longo do tempo geram contínua elevação do caixa da União, uma vez que os resultados cambiais do Bacen, que incluem os ganhos não realizados das reservas internacionais, são depositados semestralmente na Conta Única. Esses recursos, que anteriormente só poderiam ser utilizados para amortização do principal da dívida pública, a partir de 2008 podem ser também empregados para o pagamento de juros da dívida. Como consequência, o Tesouro aumenta sua margem de manobra nas despesas primárias, uma vez que os recursos que seriam utilizados para pagamento de juros podem ser redirecionados para outros fins.

Rytenband (2016) ressalta, ainda, que as alterações instituídas pela Lei $11.803 / 2008$ vão de encontro ao que recomendam as normas internacionais de contabilidade em relação ao tratamento a ser dado aos resultados de um Banco Central. 
Isso porque, ao separar o resultado do Banco Central em dois, um resultado operacional, e outro o resultado financeiro das operações com reservas cambiais depositadas no Banco Central do Brasil e das operações com derivativos cambiais por ele realizadas no mercado interno, dando tratamento diferenciado para cada um deles, a Lei estabeleceu que as variações em reais nas reservas internacionais, apesar de não ocorrerem saídas ou entradas de recursos no caixa do Banco Central, e seus valores, quando positivos, são remetidos à conta única com o Tesouro Nacional.

Em outras palavras, é como se o Banco Central tivesse um ativo avaliado em $\mathrm{R} \$$ 100 mil. Após um semestre, o ativo sofreu uma valorização e passa a valer $\mathrm{R} \$ 150 \mathrm{mil}$ a valor de mercado. O Banco Central apura, então, um lucro de $\mathrm{R} \$ 50$ mil e deposita este valor na conta única com o Tesouro, obviamente sem ter vendido o ativo, ou seja, não houve realização do ganho. Caso o mesmo ativo se desvalorizasse no mesmo período, passando a valer $\mathrm{R} \$ 50$ mil no mercado, o Tesouro seria obrigado a repassar ao Banco Central títulos públicos equivalentes ao valor do prejuízo apurado. Isso ocorre apesar de não ter havido qualquer movimentação financeira na Conta Única no período, pois nem o lucro, nem o prejuízo, foram realizados (MENDES, 2016).

Ademais, ao separar o resultado do Banco Central em dois, a Lei 11.803/2008 produziu outra incoerência: caso haja um resultado positivo nas operações cambiais de $\mathrm{R} \$$ 50 mil, e uma perda de $\mathrm{R} \$ 50$ mil no resultado operacional no mesmo período, o resultado do Banco Central deveria ser zero, ou seja, o lucro em operações cambiais anularia o prejuízo nas outras operações do Banco Central. Como resultado, não ocorreria nenhuma movimentação financeira. Uma vez, porém, que a Lei 11.803/2008 determina a apuração dos resultados separadamente, o Banco Central depositaria R\$ 50 mil na Conta Única, e o Tesouro transferiria o equivalente $\mathrm{R} \$ 50$ mil em títulos. Assim, em uma situação que originalmente não produziria qualquer transferência financeira, houve um fluxo monetário para a Conta Única, e um aumento do estoque de títulos na carteira do Banco Central, ou seja, do endividamento público (FRANCO, 2016).

Considerando o grande volume das reservas internacionais em poder do Bacen, os resultados deste oscilaram bastante, levando a um montante elevado de recursos creditados na conta do Tesouro Nacional, ao mesmo tempo em que houve grande montante de títulos emitidos pelo Tesouro para cobrir prejuízos do Bacen. Pierry (2018) alerta que a Regra de Ouro, criada com o objetivo de obrigar os governantes a manterem as contas públicas equilibradas, vem sendo atendida, desde 2005, com a ajuda do recebimento de receitas extraordinárias por parte do Tesouro Nacional, dentre elas os resultados positivos do Bacen, levando a um agravamento da deterioração da situação fiscal no Brasil.

Vários autores alertam, ainda, que a transferência de lucros e a compensação de prejuízos entre o Banco Central e o Tesouro Nacional configura financiamento implícito do Tesouro por parte do Banco Central, contrariando o parágrafo $1^{\circ}$ do artigo 164 da Constituição Federal (NUNES; NUNES, 1999; FRANCO, 2016; MENDES, 2016). Ao analisar a questão, no entanto, o Tribunal de Contas da União (2011) considerou não haver qualquer inconstitucionalidade nos mandamentos da Lei 11.803/2008.

A fim de aprimorar os fluxos financeiros decorrentes do relacionamento do Tesouro Nacional com o Bacen, foi sancionada, em 2 de maio de 2019, a Lei 13.820/2019, que dispõe sobre as relações financeiras entre a União e o Banco Central do Brasil. Tal Lei encerra a operação de equalização cambial, vigente desde 2008. 
De acordo com a nova Lei, o resultado positivo, apurado no balanço semestral do Banco Central - após a constituição de reservas -, será considerado obrigação da referida entidade com a União, devendo ser objeto de pagamento até o 10 ㅇ dia útil subsequente ao da aprovação do balanço semestral. Nesse ínterim, o resultado positivo apurado relativo às operações com reservas cambiais e derivativos cambiais, será exclusivamente destinado à constituição da reserva de resultado, a qual será utilizada apenas para cobrir os prejuízos do próprio Banco.

Desta forma, em caso de resultado negativo apurado no balanço semestral do Banco Central, este será coberto pela reversão da reserva de resultado constituída, oriunda do resultado financeiro positivo de suas operações com reservas cambiais e das operações com derivativos cambiais ocorridas em exercícios anteriores. Alternativamente, os prejuízos do Banco poderão ser cobertos pela redução do patrimônio institucional do Banco Central, ocorrendo somente até que o patrimônio líquido do Banco Central atinja o limite mínimo de $1,5 \%$ do ativo total existente na data do balanço. Apenas depois de esgotadas as reservas, e após a redução do patrimônio líquido do Banco, o eventual saldo remanescente do prejuízo poderá ser coberto pela emissão de títulos da dívida pública, quando constituirá obrigação do Tesouro Nacional para o Bacen.

A Lei 13.820/2019 estabelece ainda que, excepcionalmente, em caso de restrições severas nas condições de liquidez, as quais podem afetar de forma significativa o refinanciamento da Dívida Pública Mobiliária Interna (DPMI), mediante prévia autorização do Conselho Monetário Nacional (CMN), os recursos existentes na reserva poderão ser destinados ao pagamento da DPMI.

As mudanças estabelecidas pela Lei 13.820/2019 buscam reduzir o volume dos fluxos financeiros entre as instituições, prevenindo que o Tesouro cubra resultados não realizados financeiramente pelo Bacen, como vinha ocorrendo desde 2008. A mudança favorece a condução da política monetária e a gestão da dívida pública, além de ir ao encontro das melhores práticas contábeis internacionais (SENADO FEDERAL, 2017).

\section{CONSIDERAÇÕES FINAIS}

A Regra de Ouro foi prevista na CF de 1988 com o objetivo de melhorar a qualidade do gasto público, evitando que haja aumento de despesas correntes financiadas com a assunção de operações de crédito. A LRF reforçou a ideia de equilíbrio ao estabelecer que as operações de crédito previstas na proposta orçamentária não ultrapassem o montante das despesas de capital.

A Regra de Ouro não se trata de inovação brasileira, uma vez que, desde 1969 há, na Alemanha, regramento semelhante, restringindo as despesas correntes a um limite relacionado às despesas de capital. De fato, alguns dos princípios da LRF foram baseados em estudos e experiência de outros países, que adotaram normas visando a coibir o desvio e desperdício de recursos públicos e trazer maior transparência à gestão financeira dos Estados.

Apesar dos mandamentos constitucionais e da LRF, especialistas de finanças públicas destacam que a Regra de Ouro no Brasil vem sendo cumprida mesmo com o endividamento crescendo muito acima dos investimentos públicos. Este fato estaria re- 
lacionado ao volume elevado de receitas financeiras de que dispõe o governo federal brasileiro, dentre elas o resultado positivo do Banco Central transferido ao Tesouro Nacional.

A edição da Lei 11.803/2008 trouxe inovações quanto à forma de apuração do resultado do Bacen, por meio da institucionalização da equalização cambial. Conforme foi demonstrado neste artigo, verifica-se o impacto que tais alterações trouxeram no que se refere ao cumprimento da Regra de Ouro. De fato, depreende-se da análise dos resultados do Banco Central que, após a edição da Lei 11.803/2008, passa a apresentar seguidos resultados positivos, com exceção apenas nos anos de 2009 e 2016.

Os resultados indicam que há relevantes impactos da transferência dos resultados do Banco Central, no período de 2008 a 2019, no cumprimento da Regra de Ouro no Brasil. Da análise da relação entre esses dois conceitos, o tratamento do resultado do Bacen e o cumprimento da Regra de ouro, infere-se que as alterações da Lei ao longo do tempo geram contínua elevação do caixa da União, uma vez que os resultados cambiais do Bacen, que incluem os ganhos não realizados das reservas internacionais, são depositados semestralmente na Conta Única. Esses recursos, que anteriormente só poderiam ser utilizados para amortização do principal da dívida pública, a partir de 2008 podem ser também utilizados para o pagamento de juros da dívida. Como consequência, o Tesouro aumenta sua margem de manobra nas despesas primárias, uma vez que os recursos que seriam utilizados para pagamento de juros, podem ser redirecionados para outros fins.

\section{REFERÊNCIAS}

AFONSO, J. R. R. Responsabilidade fiscal: uma memória da lei. FGV Projetos, 2010. Disponível em: https:// bibliotecadigital.fgv.br/dspace/bitstream/handle/10438/6941/364.pdf. Acesso em: 2 maio 2020.

BAUMANN, E.; DÖNNEBRINK, E.; KASTROP, C. A concept for a new budget rule for Germany. In: CESifo Forum. München: ifo Institut für Wirtschaftsforschung an der Universität München, 2008. p. 37-45. Disponível em: file:///Users/fernando/Downloads/SSRN-id2004444.pdf. Acesso em: 1ㅇmaio 2020.

BRASIL. Lei Complementar, $n^{\circ} 101$, de 4 de maio de 2000. Estabelece normas de finanças públicas voltadas para a responsabilidade na gestão fiscal e dá outras providências. Diário Oficial da União, Brasília, DF, 5 de maio de 2000.

BRASIL. Lei, $n^{\circ}$ 11.803, de 5 de novembro de 2008. Altera a Lei no 10.179, de 6 de fevereiro de 2001, dispõe sobre a utilização do superávit financeiro em 31 de dezembro de 2007, e dá outras providências. Diário Oficial da União, Brasília, DF, 6 de novembro de 2008.

CHOTE, R.; EMMERSON, C.; TETLOW, G. The fiscal rules and policy framework. 2009. p. 81-112. Disponível em: https://www.ifs.org.uk/budgets/gb2008/08chap3.pdf. Acesso em: 1ㅇ maio 2020.

CONFEDERAÇÃO NACIONAL DAS INSTITUIÇÕES FINANCEIRAS. Com a nova lei, Tesouro pode resgatar $R \$ 70$ bi em títulos. 2019. Disponível em: https://cnf.org.br/com-nova-lei-tesouro-pode-resgatar-r-70-bi-em-titulos/. Acesso em: 30 jun. 2020.

COURI, D. et al. Estudo especial regra de ouro no Brasil: balanços e desafios. Instituição Fiscal Financeira; Senado Federal. 2018. Disponível em: http://www2.senado.leg.br/bdsf/bitstream/handle/id/540060/ EE_n05_2018.pdf. Acesso em: 10 maio 2020.

LEITE, M. A Lei de Responsabilidade Fiscal e o combate ao crime de corrupção. 2011. Disponível em: https://www.aedb.br/seget/arquivos/artigos15/17922221.pdf. Acesso em: Acesso em: 5 maio 2020.

FRANCO, G. O jogo do Papagaio. Jornal O Estado de São Paulo, maio 2016. Disponível em: http://itv.org. br/opiniao/o-jogo-do-papagaio-por-gustavo-franco. Acesso em: 25 jul. 2018.

GOBETTI, S. W. Regras fiscais no Brasil e na Europa: um estudo comparativo e propositivo. Texto para Discussão. 2014. Disponível em: https://www.econstor.eu/bitstream/10419/121671/1/815273592.pdf. Acesso em: 5 maio 2020.

GOLLO, R. D. Análise do nível de reservas internacionais dos países emergentes de 2000 a 2010. 2012. Disponível em: http://repositorio.jesuita.org.br/handle/UNISINOS/3285. Acesso em: 25 jun. 2020. 
KAFRUNI, S. Lei de Responsabilidade Fiscal completa 20 anos enfrentando desrespeito. Autores da norma alertam que, não fossem estabelecidos esses limites em 2000, a situação estaria ainda pior. Correio Braziliense, mar. 2020. Disponível em: https://www.correiobraziliense.com.br/app/noticia/economia/2020/03/01/internas_economia,831272/lei-de-responsabilidade-fiscal-completa-20-anos.shtml. Acesso em: 1을 maio 2020.

MENDES, M. J. A Lei 11.803/2008 e a Relação Financeira Tesouro - Banco Central. Brasília: Núcleo de Estudos e Pesquisas/CONLEG/Senado, fev. 2016 (Texto para Discussão no 189). Disponível em: https://www2. senado.leg.br/bdsf/bitstream/handle/id/518437/TD189-MarcosMendes.pdf?sequence=1\&isAllowed=y. Acesso em: 2 maio 2020.

MENDES, M. J. Gastos pró-cíclicos e crise fiscal. Brasil economia e governo. Finanças públicas e gestão pública, jun. 2015. Disponível em: http://www.brasil-economia-governo.org.br/2015/06/24/gastos-pro-ciclicos-e-crise-fiscal/. Acesso em: 2 maio 2020.

NÓBREGA, M. Lei de responsabilidade fiscal e leis orçamentárias. São Paulo: Juarez de Oliveira, 2002.

NUNES, S. P. P.; NUNES, R. Relacionamento entre Tesouro Nacional e Banco Central: aspectos da coordenação entre as políticas fiscal e monetária no Brasil. Brasília: Esaf, 1999. Disponível em: http://www. tesouro.fazenda.gov.br/Premio_TN/ivpremio/divida/2afdpIVPTN/NUNES_Selene_NUNES_Ricardo.pdf.

NASCIMENTO, E. R.; DEBUS, I. Lei complementar n. 101/2000: entendendo a Lei de Responsabilidade Fiscal. Brasília, DF: Secretaria do Tesouro Nacional, 2002.

PIERRY, F. Governo "pedala" há 13 anos para cumprir regra que pode levar a impeachment. Jornal Gazeta do Povo, abr. 2018. Disponível em: https://www.gazetadopovo.com.br/politica/republica/governo-pedala-ha-13-anos-para-cumprir-regra-que-pode-levar-a-impeachment-55y78omhdlbx0zzrjcoahfetk/. Acesso em: 10 maio 2020.

PIRES, M. Uma análise da regra de ouro no Brasil. 2019. Disponível em: https://repositorio.unb.br/bitstream/10482/36283/1/1809-4538-rep-39-01-39.pdf. Acesso em: 10 maio 2020.

ROSA, A.; NETO, A. G. Improbidade administrativa e lei de responsabilidade fiscal: conexões necessárias. Florianópolis: Habitus, 2001.

RYTENBAND, R. Mais contabilidade criativa: a relação entre Banco Central e Tesouro Nacional precisa mudar! Site Dinheirama, 2016. Disponível em: https://dinheirama.com/contabilidade-criativa-relacao-banco-central-tesouro-nacional-mudar/. Acesso em: 1ㅇmaio 2020.

SECRETARIA DO TESOURO NACIONAL. Relatório Contábil do Tesouro Nacional: uma análise dos ativos e passivos da União, 2018. Disponível em: https://www.tesourotransparente.gov.br/publicacoes/relatorio-contabil-do-tesouro-nacional-rctn/2018/114. Acesso em: 7 jul. 2018a.

SECRETARIA DO TESOURO NACIONAL. Informe Dívida, maio de 2018. Disponível em: http://www.tesourotransparente.gov.br/visualizacoes/regra-de-ouro. Acesso em: 29 jul. 2018b.

SENADO FEDERAL. Projeto de Lei do Senado (PLS) 314. 2017. Disponível em: https://legis.senado.leg.br/ sdleg-getter/documento?dm=7162995\&disposition=inline. Acesso em: 10 maio 2020.

TAVARES, M. A. et al. Princípios e regras em finanças públicas: a proposta da Lei de Responsabilidade Fiscal do Brasil. Brasília: Seminário Cepal, 1999.

TRIBUNAL DE CONTAS DA UNIÃO. Acórdão 1.259/2011 - TCU - Plenário. Relator ministro Walton Alencar. 2011. Disponível em: https://contas.tcu.gov.br/etcu/ObterDocumentoSisdoc?seAbrirDocNoBrowser=true \&codArqCatalogado=2137536\&codPapelTramitavel=45742239. Acesso em: 2 maio 2020. 